\title{
Postpartum Depression
}

National Cancer Institute

\section{Source}

National Cancer Institute. Postpartum Depression. NCI Thesaurus. Code C92852.

A type of clinical depression that occurs after childbirth. 